\title{
Branquitude e Educação: Um Estudo com Professoras de Escolas Públicas
}

\author{
Anna Luiza Barbosa Martins* \\ Universidade Federal Fluminense - UFF, Niterói, RJ, Brasil \\ ORCID: https://orcid.org/0000-0001-8520-3015 \\ Maria Helena Rodrigues Navas Zamora** \\ Pontifícia Universidade Católica do Rio de Janeiro - PUC-RJ, Rio de Janeiro, RJ, Brasil \\ ORCID: https://orcid.org/0000-0003-2929-3268
}

\begin{abstract}
RESUMO
O artigo está baseado em uma pesquisa, concluída em 2018, que estudou a identidade racial branca tal como é percebida por professoras atuantes em escolas do município do Rio de Janeiro, selecionadas por amostra de conveniência. O objetivo foi investigar como essas educadoras, autodeclaradas brancas, percebem sua própria branquitude em relação a seu público na escola - em sua maioria alunos negros, e o impacto dessa diferença racial em sua prática profissional. $\mathrm{O}$ trabalho considera o racismo estrutural no Brasil e consiste em um diálogo entre referenciais teóricos dos Estudos Críticos da Branquitude, da Psicologia Social Crítica e da Educação Libertadora, usando como técnica entrevistas individuais, devidamente analisadas pelo método da Análise de Conteúdo. Percebeu-se tanto a necessidade de que os educadores brancos se vejam como racializados, quanto a relevância de um aprofundamento das discussões sobre relações raciais na escola. Evidenciou-se, também, a importância de ações coletivas e políticas públicas adequadas para lidar com as reverberações provocadas pela desigualdade racial no âmbito escolar.
\end{abstract}

Palavras-chave: branquitude, educação, raça, escola pública, psicologia social.

\section{Whiteness and Education: A Study with Teachers of Public Schools}

\begin{abstract}
The article is based on a survey, completed in 2018, which had studied white racial identity as perceived by teachers working in schools in the city of Rio de Janeiro, selected by convenience sample. The objective was to investigate how these educators, self-declared white, perceive their own whiteness in relation to their audience at school - mostly black students, and the impact of this racial difference on their professional practice. The work considers structural racism in Brazil and consists of a dialogue between theoretical references of Critical Studies on Whiteness, Critical Social Psychology and Liberating Education, using as technique individual interviews, properly analyzed by the Content Analysis method. It was perceived both the need for white educators to see themselves as racialized, as well as the relevance of deepening discussions about race relations at school. The importance of
\end{abstract}


collective actions and appropriate public policies to deal with the reverberations caused by racial inequality in the school environment was also evident.

Keywords: whiteness, education, race, public school, social psychology.

\section{Blanquitud y Educación: Un Estudio con Docentes de Escuelas Públicas}

\section{RESUMEN}

El artículo se basa en una investigación, completada en 2018, que estudió la identidad racial blanca según la perciben los maestros que trabajan en las escuelas de la ciudad de Río de Janeiro, seleccionados por muestra de conveniencia. El objetivo era investigar cómo estos educadores, autodeclarados blancos, perciben su propia blanquitud en relación con su audiencia en la escuela, en su mayoría estudiantes negros, y el impacto de esta diferencia racial en su práctica profesional. El trabajo considera el racismo estructural en Brasil y consiste en un diálogo entre referencias teóricas de Estudios Críticos sobre Blancura, Psicología Social Crítica y Educación Liberadora, utilizando como técnica entrevistas individuales, debidamente analizadas por el método de Análisis de Contenido. Se percibió tanto la necesidad de que los educadores blancos se vean a sí mismos como racializados, como la relevancia de profundizar las discusiones sobre las relaciones raciales en la escuela. También se evidenció la importancia de acciones colectivas y políticas públicas adecuadas para enfrentar las repercusiones que la desigualdad racial genera en el ámbito escolar.

Palabras clave: blanquitud, educación, raza, escuela pública, psicología social.

Este artigo é fruto de uma pesquisa de mestrado feita entre 2017 e 2018, cujo objetivo foi investigar como a identidade racial branca é percebida e vivenciada por professoras autodeclaradas brancas que atuam no Ensino Fundamental em escolas municipais do Rio de Janeiro. A busca pelos sujeitos não impôs nenhuma restrição em termos de gênero; no entanto, apenas docentes mulheres se voluntariaram para as entrevistas.

Historicamente estigmatizada como a escola dos filhos dos pobres, a escola pública tem maioria de alunos negros (Veiga, 2008). Sendo assim, a relevância da pesquisa reside em explorar como docentes brancas se percebem diante de um público-alvo de maioria nãobranca, e quais as implicações decorrentes dessa relação. Assumem-se como referenciais teóricos os Estudos Críticos da Branquitude (Cardoso, 2011, 2017; Carone \& Bento, 2002; Schucman, 2014), a Psicologia da Libertação e a Psicologia Sócio-Histórica (Bock, Gonçalves, \& Furtado, 2015), bem como a Educação Libertadora de Paulo Freire (Freire, 1999, 2005, 2015). 
$\mathrm{O}$ artigo conjuga o saber com a demanda social latente de uma resposta às persistentes desigualdades raciais e ao sofrimento psíquico por elas causado. A partir de um enfoque que compreende a escola como instituição social capaz tanto de reproduzir quanto de romper com discursos ideológicos em prol das classes dominantes (Guzzo \& Ribeiro, 2019), aborda-se a questão das relações raciais por um ângulo diferente da mais tradicional problematização, ou seja, do negro posto como objeto (Bento, 2002; Oliveira, 2007; Piza, 2002).

Raça é uma categoria injustificável em termos biológicos, mas permanece operante no meio social, legitimando desigualdades materiais e simbólicas (Carone \& Bento, 2002; Schucman, Mandelbaum, \& Fachim, 2017; Schucman, 2014). Por racismo, compreende-se "uma forma sistemática de discriminação que tem a raça como fundamento, e que se manifesta por meio de práticas conscientes ou inconscientes que culminam em desvantagens ou privilégios para indivíduos, a depender do grupo racial ao qual pertençam” (Almeida, 2018, p. 25).

A realidade brasileira é fortemente marcada pelo racismo; reproduzindo a (i)lógica das hierarquias raciais. $\mathrm{O}$ negro continua sendo representado pelo estereótipo do bandido e constitui a maior parte da população carcerária brasileira. Ainda é visto como perigoso e é o que mais morre assassinado em geral jovem (Waiselfisz, 2016). Já a mulher negra tem sido hipersexualizada, é a mais violentada e também a mais "matável" das mulheres (Waiselfisz, 2015; Instituto de Pesquisa Econômica Aplicada [Ipea] \& Fórum Brasileiro de Segurança Pública [FBSP], 2017).

No tocante às contribuições da Psicologia, conforme apontam Santos, Schucman e Martins (2012), durante todo o século XX, o saber psicológico se viu diante da necessidade de pensar e produzir teorias sobre as relações raciais em âmbito nacional. Nos anos 90, começaram a ganhar força no campo psi as discussões sobre os sujeitos brancos e suas implicações nas relações étnico-raciais.

O que se propõe é o reconhecimento do protagonismo do branco nos processos de enrijecimento de hierarquias raciais e de omissão diante dos seus privilégios. Devido ao legado colonizador, não é comum que o branco reflita sobre si enquanto grupo racializado. Trata-se então de falar do lugar do branco, do status que ocupa na sociedade, do processo que o torna modelo e referência universal de beleza, inteligência, moralidade e outras características positivas (Carone \& Bento, 2002). Esta é a base do conceito de branquitude.

Não há consenso sobre a definição de branquitude. Diz respeito a um fenômeno diverso, mutável e complexo. Assim, não é possível falar de algo tal como "uma identidade racial branca" que atravessa contextos históricos e sociais. Contudo, com base no que parece 
comum nas produções dos variados estudiosos (Cardoso, 2017; Carone \& Bento, 2002; Jesus, 2014, 2017; Oliveira, 2007; Schucman, 2014), assume-se a concepção de branquitude como um lugar de privilégios tanto simbólicos quanto materiais, que influencia diretamente o modo de o sujeito se reconhecer, estar e agir no mundo. Trata-se da identidade racial branca que se reconstrói no tempo e nas sociedades, conforme recebe influências, mas que permanece sendo um lugar estrutural ocupado pelo branco, que se situa acima dos demais, alcançando o status de ideal e norma.

Posto isso, o artigo propõe investigar como a branquitude de docentes é percebida por elas, como atravessa suas práticas profissionais e quais as suas implicações na formação. É na escola que o indivíduo amplia a socialização e, especificamente na escola pública, onde tem a oportunidade de conhecer a realidade de sujeitos diferentes entre si. Também é na escola que a criança e o adolescente têm a oportunidade de se apropriar do conhecimento, diminuindo os riscos de alienação futura quando a educação é libertadora (Freire, 2005, 2015).

Uma das questões exploradas pela pesquisa foi a possibilidade de docentes de perspectiva crítica questionarem a estrutura racista. É nesse sentido que se utiliza o referencial freiriano para pensar a educação e o papel do professor (Freire, 2005, 2015). Para o autor, sua ação pode contribuir para a desconstrução de ideias naturalizadas - inclusive o racismo.

\section{Metodologia}

Foi desenvolvida uma pesquisa exploratória, por meio de revisão bibliográfica e de estudo de campo constituído por escolas públicas municipais de diferentes Coordenadorias Regionais de Educação - CREs, nome adotado na Secretaria Municipal de Educação da cidade do Rio de Janeiro. Das dez CREs em que a cidade está dividida, quatro foram contempladas pela amostra estudada. Foram realizadas entrevistas individuais, de roteiro semiestruturado, com dez professoras que se autodeclaram brancas e que lecionam na rede mencionada, atendendo estudantes do sexto ao nono ano do Ensino Fundamental. As entrevistas tiveram duração média de 35 minutos, foram gravadas em áudio e posteriormente transcritas e analisadas. O grupo de entrevistadas é formado por duas professoras de História; duas de Artes; uma professora de Português; uma de Português e Inglês; uma de Inglês; uma professora de Matemática; uma de Ciências Naturais e uma de Espanhol.

O projeto de pesquisa foi avaliado e aprovado pelo Comitê de Ética em Pesquisa da Pontifícia Universidade Católica do Rio de Janeiro (PUC-Rio), sob o Parecer No 03/2018. Ademais, as participantes assinaram um Termo de Consentimento Livre e Esclarecido 
(TCLE), ficando uma via com a pesquisadora e outra com a entrevistada. O material produzido na pesquisa - os TCLEs e as gravações transcritas das entrevistas - será armazenado por cinco anos pelo Departamento de Psicologia da universidade PUC-Rio. Os nomes das entrevistadas foram trocados por nomes fictícios para manter o sigilo.

A técnica escolhida para a análise dos dados foi a Análise de Conteúdo proposta por Bardin (2011). Com as entrevistas já transcritas, os dados foram distribuídos em categorias temáticas obedecendo ao critério semântico para sua codificação. Deste processo, surgiram as seguintes categorias: Autorreflexão; Relação Professor-Aluno; e Práticas Escolares. O artigo tratará apenas das categorias Autorreflexão e Relação Professor-Aluno. Após a categorização, foi realizada uma descrição do material coletado seguido de inferências dos resultados (Bardin, 2011). Por fim, os resultados obtidos foram interpretados com respaldo na fundamentação teórica adotada.

\section{Resultados}

Grande parte das entrevistadas mostrou estranhamento, desde o primeiro contato, ao compreender que o objeto de estudo era a identidade racial branca. Elas foram convidadas por contato telefônico ou e-mail. O objetivo da pesquisa foi então apresentado de forma sucinta. O roteiro de entrevista continha perguntas sobre a percepção delas acerca de sua pertença racial e da dos alunos, sobre a experiência pessoal e profissional enquanto alguém da raça branca, sobre privilégios da brancura e sobre as formas como o tema das relações raciais é tratado no ambiente de atuação profissional. A tendência percebida foi que, mesmo diante de perguntas direcionadas para sua própria raça e para o lugar do branco educador, as entrevistadas evitavam o assunto para mencionar situações de racismo na escola, para falar da negritude dos alunos ou reafirmar a importância da herança africana na cultura brasileira.

Outro ponto a ser destacado foi a recorrente sugestão de que se entrevistassem os professores negros. Foi necessário reafirmar que o interesse era fugir do tradicional negrotema e implicar o branco nas reflexões acerca das desigualdades raciais. Apesar do estranhamento inicial, a maior parte das educadoras compreendeu, aos poucos, a proposta. No entanto, pensar a respeito de si enquanto pessoas racializadas não pareceu fácil para elas. 


\section{Autorreflexão}

Três das dez entrevistadas reconheceram-se brancas prontamente quando perguntadas sobre sua identidade racial. Uma delas atrelou as vantagens experimentadas ao longo da vida diretamente à sua brancura: "eu me reconheço como branca e percebo que durante toda a minha vida eu tive privilégios" (Bianca).

Por outro lado, falar de sua pertença racial foi um exercício difícil para as demais entrevistadas. Um aspecto importante em relação a essa declaração de pertença é que, embora se reconhecessem como brancas fenotipicamente, algumas afirmaram que se identificavam com os alunos (não-brancos), seja no sentido de um exercício de empatia, seja no sentido de uma afirmação política. Essas participantes chegaram a mencionar sentir constrangimento ao se perceberem brancas, diante de situações de opressão vividas e relatadas por seus alunos ou diante de reflexões sobre as desigualdades sociais estruturais presentes em nossa sociedade. Um fragmento pode mostrar essa vergonha ao perceber seus privilégios, advindos da cor de sua pele, diante de alguém que não poderia tê-los:

Aí essa mãe chegou pra ele [aluno] e falou assim: "Olha, você já é preto... pobre... Você tem que estudar pra ser alguma coisa na vida." O menino abaixou a cabeça, se sentindo tão humilhado... E eu... me senti tão humilhada quanto ele, mas por eu ser branca... entendeu? (Flávia).

O sentimento de Flávia de humilhação aponta para a percepção de que o estudante precisaria se esforçar muito mais caso desejasse "ser alguma coisa na vida". Ela própria, sendo branca, não enfrentou essa mesma pressão em sua vida, e, naquele momento, foi inevitável encarar e reconhecer seu lugar privilegiado.

Três das dez participantes mostraram pouca reflexão em torno de sua pertença racial. Afirmaram que não pensam a respeito ou que julgam a classificação racial como algo desnecessário. Para uma delas, a diferenciação racial é um dos fatores que fomentam a discriminação. As outras duas afirmaram não compreender qualquer diferenciação já que no Brasil a mistura de raças se faria presente. $\mathrm{O}$ argumento da miscigenação se articula com a exposição de Bento (2002) que, ao denunciar a ideologia do branqueamento e a falácia da harmonia racial no Brasil, aponta para a tendência do branco de esquivar-se da discussão e isentar-se das responsabilidades das práticas racistas históricas. 
As três professoras que entenderam a classificação racial como algo sem sentido utilizaram o argumento da miscigenação para defender que não seriam realmente brancas, apesar do fenótipo. As outras sete também mencionaram, indiretamente, a mistura étnica como algo de que são fruto, mas chama atenção o fato de que estas são capazes de localizar sua origem étnica-geográfica. A maioria delas consegue dizer algo de seus antepassados, sua origem e qual cultura predomina em suas tradições familiares o que, para afrodescendentes, torna-se praticamente impossível diante do apagamento de suas origens pela escravidão.

Outro tema presente no discurso da maior parte das participantes foi a menção ao que elas chamaram de "choques de realidade". Usaram essa expressão para se referir a momentos em que se deram conta de que sua brancura gerava privilégios e que as oportunidades que tiveram e a forma como foram tratadas na vida não eram comuns aos de outros fenótipos.

[Houve] Uma cena que me marcou. (...) essa menina ainda tá estudando comigo, agora. (...) Aí ela sentou comigo e falou assim "tia eu adoro a sua cor, eu queria tanto ter a sua cor!" Ai, que dó que me deu! Eu falei assim "Que isso, sua cor é linda! É linda, eu quero ter uma filhinha igual a você" eu brinquei com ela. Mas ela "Ah, mas você é tão bonita!”... (PAUSA) Que é isso! Quem foi que introjetou na cabeça de uma criança, que uma cor é melhor que outra? (Helena).

Ao se relacionarem com pessoas de outras raças, foi possível para elas se aproximar de problemas desconhecidos e questões não consideradas anteriormente. Tais experiências lhes deram a oportunidade de refletir sobre os significados de ser branco em seu exercício docente.

A gente tá ali pra qualquer coisa. Então, assim, ser educador branco, eu, eu... eu não... pensei nisso por muito tempo. Não pensei que isso fosse necessário. Mas, com a forma com que determinadas coisas vão tomando rumo, a gente tem que pensar nisso o tempo todo. Você tem que se reconhecer o tempo todo, você tem que saber exatamente qual é o teu lugar, qual é a tua posição, até mesmo pra não ficar num... passeando por uma área, assim... ou hipócrita, né... ou preconceituosa... (Daniele).

A entrevistada segue falando sobre o trabalho do professor, como exige reflexão e autocrítica. É possível que, ao falar de hipocrisia, Daniele queira dizer que é necessário que a prática seja condizente com o discurso antirracista. Uma vez percebido seu lugar de 
privilégios, é preciso questioná-lo continuamente, e não supor que seus alunos não-brancos possam usufruir das mesmas vantagens.

As entrevistadas consideraram que a maioria de seus alunos são pretos ou pardos. Atuar como professora branca diante de alunos não-brancos implica questões importantes. Por fim, também foram mencionadas as responsabilidades e as potências inerentes a esse lugar de educador. No que concerne a responsabilidades, uma das entrevistadas apontou:

Eu acho que independente de qual raça e cor o professor seja, ele tem que entender, buscar, pesquisar essa história africana... independente também da matéria que ele leciona. Não é só o professor de História e, no máximo, Geografia, que tem que entender isso. Porque a gente sabe quem é o público, a maioria é negra e vinda de favela ou comunidade pobre. (Alice)

Quanto às possibilidades, é comum no universo acadêmico, especialmente entre os estudos e indivíduos críticos, que a educação seja concebida como um campo de rompimento de lógicas e de estímulo de novas formas de compreender e se relacionar com o mundo. No entanto, para o profissional imerso no cotidiano escolar, muitas vezes desgastante, a percepção dessa potência pode ir se desvanecendo com o tempo. Apesar disso, cinco entrevistadas expressaram enfaticamente o quanto acreditam no potencial de transformação do professor da educação básica na rede pública.

Mas eu acho que a gente tem que pensar, compreender, entender as engrenagens do sistema e desconstruir [...]. Eu tento desenvolver nos meus alunos consciência social [...]. É isso que faz eu me sentir menos mal. Eu tento, né? Podia estar ali só reproduzindo conteúdo... (Cecília)

Eu acho que o nosso lugar de educador é um lugar muito potente, né, é um lugar cheio de possibilidades, um lugar que a gente não pode dizer que é desimportante, né. Apesar da gente ser levado a acreditar nisso. Esse é um lugar de muita potência, porque os nossos alunos escutam a gente. Eles podem até fingir que não estão escutando, mas escutando eles estão. (Bianca)

Considerando o lugar de educador como espaço de potência, essas entrevistadas falaram de seus esforços para ocupá-lo de forma antirracista. Não mencionaram discussões ou 
práticas que trabalhassem a identidade branca e seus privilégios, mas destacaram o esforço de abordar o conteúdo de forma que consideram crítica. Falaram também de atividades como rodas de conversa sobre racismo, desfiles de "moda negra" e trabalhos literários baseados em autores negros.

\section{Relação Professor-Aluno}

As entrevistadas, em sua maioria, apontaram seus alunos como sujeitos portadores de conhecimentos preciosos, que lhes ensinam constantemente. O estudante é visto como alguém ativo, sujeito de direitos e de desejos, que pode ensinar o professor tanto quanto por ele é ensinado. Apesar disso, várias professoras falaram da possibilidade de o educador não ter essa perspectiva. A maior parte falou do racismo no cotidiano escolar, a partir do posicionamento do professor que naturaliza as desigualdades e também do quanto a relação desse tipo de professor com os estudantes pode ser geradora de sofrimento psíquico.

As professoras dizem que a instituição escola pública não é racista, que o sistema de ensino público não discrimina alunos por serem brancos, negros, orientais ou indígenas. Mas reconhecem que existem colegas racistas e que essas práticas, embora não sejam institucionalizadas, podem acontecer dependendo de cada professor:

No sistema, em si, não acho que tenha diferença. (...) Agora, questão pessoal, de profissionais, de professores, aí eu não sei, entendeu? (...) Mas aí eu acho que isso é de cada um, da pessoa, do professor e não do sistema público de ensino, entendeu? (Íris).

Também foi afirmado que frequentemente a relação professor branco-aluno negro é marcada pela distância, tanto simbólica quanto corporal. Foi possível observar que a linguagem do aluno ilustra esse distanciamento; especialmente por meio dos pronomes de tratamento - mesmo para se referir a professoras muito jovens, os estudantes usam "dona", "senhora", etc. É possível considerar que isso se dá não apenas por respeito. Tais termos remetem à cultura escravocrata do país em que brancos têm ocupado historicamente o lugar de "donos" e "senhores", que devem ser tratados com deferência, sobretudo pela população negra. Referem-se ao status do branco como superior, o ideal e a norma, são efeitos da branquitude em ação (Cardoso, 2017; Carone \& Bento, 2002; Schucman, 2014).

Ademais, existe a fantasia de que o professor ocupa um lugar de saber que é quase inalcançável. Para além disso, o ser branco aparece ainda carregado de muitas idealizações 
para os alunos, como estar diretamente atrelado a possuir recursos financeiros, a gostar de produções culturais específicas (sofisticadas, elitistas) e até mesmo ser considerado bonito.

Talvez por ser branca, por ter olhos claros, o cabelo liso, as crianças, principalmente o sexto ano (...) eles vinham até a mim e eles queriam mexer no meu cabelo, sabe? Ficava assim: "Professora, o seu olho é verde!". E eu acho engraçado que esse ano uma aluna falou pra mim assim: "Professora, a senhora parece rica!”. (Eliana)

Esse "achar engraçado" pode ser compreendido tanto como surpresa, curiosidade e estranhamento, como também como uma postura de neutralidade ou de não-implicação diante do apontamento de um privilégio característico da branquitude.

Além disso, as professoras também falaram sobre um aspecto fundamental da relação professor-aluno: a identificação. Elas afirmaram que os lugares de poder na escola costumam ser ocupados por pessoas brancas: os professores, os diretores, os representantes da Secretaria de Educação. Em contrapartida, as funções de merendeira, auxiliar de serviços gerais, porteiros, são ocupadas por pessoas negras. Não há nada de errado nestas profissões, mas as entrevistadas afirmaram que os alunos apenas naturalizam esses lugares, sendo as primeiras ocupações mais reconhecidas socialmente e melhor remuneradas do que as segundas. De acordo com as professoras, é como se o lugar do branco fosse naturalmente superior em salários e prestígio, e o do negro, naturalmente subalterno, de modo que as crianças e adolescentes não aprendem a questionar. E, ao se identificarem apenas com as merendeiras, porteiros e serventes, os estudantes não conseguem acreditar que podem ser professores, diretores, técnicos.

As entrevistadas apontaram para a necessidade de que haja cada vez mais professores negros nos espaços escolares, especialmente nos ambientes da educação básica. Segundo elas, esse convívio, a existência desses sujeitos nesses espaços, possibilitaria o sentimento de representatividade e, consequentemente, de identificação.

(...) reconhecimento com o professor, à primeira vista. O aluno perceber que consegue chegar em algum lugar. Por exemplo, o professor negro pode servir de espelho para ele [aluno], "olha onde é que está esse professor, olha o conhecimento que esse professor tem, estudou muito pra estar ali’... Já com o professor branco ele não vai ter esse espelho num primeiro momento. De repente nem nunca, não sei... (Alice) 


\section{Discussão}

O primeiro ponto a ser considerado é a própria dificuldade do sujeito branco em se reconhecer racializado, já que não pensar sobre si e não reconhecer-se nesse lugar é a regra (Bento, 2002; Miranda, 2017; Piza, 2002). Um dos privilégios da brancura, como foi dito, é o de ser colocado em posição de norma, de ideal, de universal. Neste sentido, o que ocorre é a racialização do outro, do não-branco, o que se pronuncia como consequência de processos históricos - como políticas higienistas e eugenistas - que influenciam diretamente a autopercepção racial dos sujeitos (Serra \& Schucman, 2012).

A maior parte das entrevistadas teve dificuldade em falar do lugar de pessoa branca, seja por posicionamento político, por apelar ao argumento da miscigenação ou por julgar que a classificação racial não é algo que faça sentido - nesses dois últimos casos, desresponsabilizando-se frente a lógicas racistas históricas (Bento, 2002) e desconsiderando o conceito de raça operante no nível social (Schucman, Mandelbaum, \& Fachim, 2017; Schucman, 2014).

O tema da identidade racial branca tem sido cada vez mais discutido nos últimos anos (Cardoso, 2011), podendo ser classificado como uma emergência no campo acadêmico. No entanto, na prática, essa compreensão está muito distante do imaginário das pessoas, inclusive dos brancos - tenham eles uma perspectiva crítica ou não quanto às desigualdades raciais. Assim, o estranhamento era algo esperado, de forma que a própria pesquisa no campo pode ser entendida como uma estratégia de intervenção, no sentido de fomentar essa reflexão nas entrevistadas, fazendo-as olhar para si mesmas e para sua condição de educadoras e brancas.

De acordo com Carone e Bento (2002), o branco chega a reconhecer que existe desigualdade racial, pode mesmo denunciar o racismo, mas raramente se implica como parte do problema. Segundo as autoras, é como se houvesse um acordo subliminar entre os brancos de não se reconhecerem como integrantes desse todo que se reproduz ao longo da história tornando o racismo apenas um problema do negro:

(...) eles reconhecem as desigualdades raciais, só não associam essas desigualdades raciais à discriminação e isto é um dos primeiros sintomas da branquitude. Há desigualdades raciais? Há! Há uma carência negra? Há! Isso tem alguma coisa a ver com o branco? Não! (Bento, 2002, p. 27, grifos das autoras). 
No caso das entrevistadas, apenas duas dentre as dez falaram ser possível que o branco encontre desvantagens simplesmente por sua cor de pele, dando o exemplo das cotas raciais. Sete das dez educadoras mostraram compreender a importância da questão. Dentre estas, não foi difícil perceber que já se começou a reconhecer o papel do branco no problema, especialmente quando mencionam o branco como "colonizador" e "opressor". A maior dificuldade foi reconhecer-se racializado - fazendo parte de um grupo que usufrui de privilégios historicamente construídos.

Para Miranda (2017), é possível e comum que o sujeito branco passe por um período de inconsciência de sua situação de privilégios e de ausência de autocrítica o que ele denomina de "invisibilidade"; por outro lado, depois que o sujeito se dá conta de que possui vantagens é possível que ele assuma uma posição dissimulada, de omissão diante dessa percepção chamada por Miranda de "neutralidade". Essa neutralidade é uma das interpretações possíveis para a fala de Eliana sobre "achar engraçado" os estudantes dizerem que ela parece rica por conta do cabelo liso e dos olhos claros.

Além disso, os "choques de realidade", mencionados por Cecília e Helena, parecem ilustrar exatamente o período de invisibilidade teorizado por Miranda (2017), quando o sujeito passa para a consciência podendo se enquadrar na neutralidade ou assumir uma postura antirracista. Esse processo corresponde à metáfora do choque com a porta de vidro, descrito por Piza (2002), quando o sujeito que passa a se reconhecer como racializado parece sofrer o impacto com uma porta de vidro nunca vista.

Os significados de ser branco no discurso de todas as entrevistadas aparecem diretamente atrelados a vantagens e privilégios. Esse é o único ponto de consenso. Nenhuma professora negou o fato de sujeitos brancos serem privilegiados nas mais diversas atividades de seu dia a dia e nos mais diferentes ambientes. Algumas professoras também incluíram nesse espectro a figura do branco colonizador - o que não é uma representação positiva, mas opressora. Apesar disso, as falas em geral aproximaram o branco a características como acesso à educação e à saúde, melhores condições financeiras, liberdade de ir e vir e, até mesmo, ao simples fato de "ser alguém". A branquitude, portanto, ainda é apresentada como lugar de superioridade (Carone \& Bento, 2002). Conforme aponta Bianca: "Pro senso comum, branco é alguém, basta ser branco".

Segundo Jesus (2017), a brancura confere status para além dos corpos. O acesso a educação, oportunidades de emprego e realização pessoal é mais difícil para a população negra do que para a população branca. E isso também deve ser visto como um problema do 
branco (Bento, 2002). Quando Flávia diz ter se sentido humilhada diante de um aluno negro que precisa multiplicar esforços, ela parece ter sido confrontada com esse fato.

E como compreender o lugar desse sujeito branco ocupando a posição de educador no ambiente escolar? A escola pública, na medida em que agrega diferenças, pode ser compreendida como importante espaço de resistência (Guzzo \& Ribeiro, 2019). É o lugar onde os professores podem desconstruir ideias tidas como inquestionáveis para si e para os alunos. A relação professor-aluno pode representar o espaço de confiança para uma efetiva troca de saberes e construção de outras realidades no campo das relações raciais. Conforme pontua Bianca: "Eu acho que a escola é um lugar perfeito pra se discutir isso, né. As crianças estão lá todos os dias, quatro horas por dia, vamos começar a mudar daí". Nesse sentido, a potência do professor ganha destaque, pois é a partir da reflexão e da autocrítica que o rompimento com a "educação bancária", denunciada por Freire (2005), pode se dar.

Sobre isso, quando Daniele fala sobre a necessidade de refletir constante e criticamente como educadora branca para não agir de forma "hipócrita", ela remonta ao conceito de branquitude crítica de Cardoso (2017). O branco crítico, para o autor, desaprova publicamente o racismo, mas muitas vezes convive com o Outro por precisar e de forma geral não desaprova o privilégio branco. O que Daniele parece dizer é que é necessário questionarse em relação a isso também. Além de se dizer antirracista, é necessário interpelar-se sobre os efeitos que o racismo estrutural gera no branco, sobre as próprias contradições e as consequências disso como educador. Assim, a prática deixa de ser alienada e alienante.

Poucas instituições têm importância tão fundamental na formação de um sujeito quanto a instituição escolar. Sobretudo na infância, essas instituições possuem autoridade e legitimidade tais que facilmente podem lançar bases profundamente arraigadas em termos de conceitos sobre si e sobre o outro. Daí advém a responsabilidade que o ambiente escolar e seus agentes têm na formação das crianças e dos adolescentes. Esse espaço e esses agentes são atravessados pela lógica que rege a instituição escolar gerando diferentes consequências na formação oferecida aos estudantes (Guzzo \& Ribeiro, 2019).

É possível afirmar que a escola pública representa determinados interesses e projetos que não necessariamente estão de acordo com os interesses da classe pela qual é composta. Segundo as entrevistadas, a maior parte dos frequentadores da escola pública são advindos da classe trabalhadora, composta por alunos pretos e pardos. Portanto, as desigualdades social e racial passam a figurar como duas faces de uma mesma moeda.

Crianças vindas de famílias pobres são frequentemente as que encontram menos êxito no mundo acadêmico. São as menos consideradas nos planejamentos políticos das escolas, 
menos compreendidas em suas especificidades por professores preocupados com o cumprimento de programas e o alcance de metas institucionais. Por outro lado, são as que mais dependem da escola para obter sua educação (Connell, 1995).

Assim, a escola brasileira funciona como instrumento de dominação - sobretudo a escola pública, que se dirige direta ou indiretamente à classe trabalhadora (Conceição \& Zamora, 2015; Penteado \& Guzzo, 2010). A serviço do capital, o espaço escolar acaba por reproduzir desigualdades sociais promovendo uma educação para a alienação que, não apenas concorda, como também defende a falácia do merecimento e da possibilidade sempre presente de superação de limites e dificuldades externas ao indivíduo.

Um dispositivo fundamental para a formação dos sujeitos, como é o sistema educacional, certamente é atravessado pelo racismo e pelo pacto (in)consciente da branquitude (Bento, 2002) que paira não só na sociedade consumista-capitalista, mas também na práxis de muitos educadores. Além disso, considerando-se que os estudantes da educação básica estão em situação peculiar de desenvolvimento, os efeitos de práticas discriminatórias podem ser mais significativos.

Se alienante e acrítica, a escola pública exerce a função ideológica de reprodução do capitalismo. Isso é, por meio de um mascaramento da realidade, dado por um corpus de representações úteis para a classe dominante, a população é convencida, por meio da educação, de que se houver mérito e esforço pessoal é possível construir uma sociedade justa economicamente e "ter sucesso". Contudo, os brancos acreditam nisso desfrutando de privilégios relativos à cor de sua pele. Assim, racismo e capitalismo se retroalimentam numa relação em que o branco, sua suposta superioridade e os privilégios daí decorrentes permanecem intocados, invisíveis ou, na melhor das hipóteses, não-problematizados.

Se, por um lado, a educação pode ser alienante, também é possível compreendê-la como prática emancipadora (Penteado \& Guzzo, 2010), e a maioria das entrevistadas parece acreditar nisso. É possível pensar um modelo de educação que conscientize o homem de sua intervenção sobre os processos sociais, que fale sobre a historicidade dos fenômenos e das possibilidades de mudança. É possível uma prática educadora que não dissocie e hierarquize trabalho manual e intelectual, assim como não o faça com as diferentes raças, e que promova reflexão crítica e autocrítica. A educação pode ser voltada para a construção da consciência e da autonomia do sujeito sobre seu lugar ativo nos processos que o engendram (Freire, 1999).

Tendo afirmado, portanto, um panorama acerca da educação, a pergunta que emerge é: e o que a Psicologia tem a ver com tudo isso? A fala de uma das entrevistadas responde bem: “(...) a educação pública, ela precisa de uma equipe integrada trabalhando com a gente, 
porque nós não somos especialistas assim nessas áreas de psicologia, das emoções. Então a escola, falta à escola, à rede como um todo, esse apoio" (Íris).

Íris dá subsídios para uma discussão fundamental: apesar do crescente interesse da Psicologia no campo das políticas públicas nas últimas décadas, é indispensável que, na prática cotidiana, esses profissionais estejam presentes e acessíveis.

A Psicologia, ao longo de sua história brasileira, é um saber que tem se comprometido com as elites (Bock, 2009). A profissão se estabeleceu num molde clínico-individual, que ainda atende majoritariamente um perfil específico: pessoas de classe média ou média-alta, com demandas geralmente individuais. É claro que, em se tratando de sofrimento psíquico, tudo deve ser acolhido e cuidado pelo psicólogo com respeito. O que se questiona é a tendência a se permanecer restrito a essas populações e a demandas individualizadas.

Existem demandas sociais e sofrimento psíquico advindos de estruturas societárias discriminatórias. Conforme Bock (2009), a Psicologia tem criado ideologia, ocultando a produção social do ser humano e de seu mundo psicológico. Com explicações mecanicistas e psicologizantes, tem-se ignorado elementos sócio-históricos, como o racismo estrutural, que interferem diretamente no psiquismo dos indivíduos e em sua organização social.

Romper com isso exige uma reflexão crítica sobre a realidade e, levando-se em consideração a configuração da população, a necessidade do estudo das relações de classe e raça. De acordo com a PNAD 2017 (Instituto Brasileiro de Geografia e Estatística [IBGE], 2017), a desigualdade de renda atinge a população de maneiras diferentes, de acordo com sua composição por cor ou raça. Os dados da PNAD apontam que entre as pessoas com os $10 \%$ menores rendimentos, pretos e pardos compunham 78,5\%, contra 20,8\% de brancos. Já entre os $10 \%$ maiores rendimentos, pretos e pardos eram somente $24,8 \%$. A pobreza no Brasil tem cor. E a escola pública também.

Não é possível pensar em formação subjetiva da classe trabalhadora que não passe pelo equipamento escolar. E a classe trabalhadora é em sua maioria negra, o que torna a discussão sobre as relações raciais no âmbito escolar necessária e urgente. Sendo assim, é papel da Psicologia Social compreender como se dão esses processos de configuração da desigualdade, bem como apontar para a existência de sofrimento psíquico advindo dessa condição sociopolítica. Ser negro no Brasil é um processo de muito custo emocional geralmente ignorado pelos saberes tradicionais, pela academia, pelos consultórios psicológicos e pela educação.

Apesar de propostas ultraconservadoras crescentes no campo da educação, existe grande força nos professores em sua atuação cotidiana. A desconstrução de paradigmas, o 
questionamento de conceitos naturalizados e da visão reprodutora de práticas racistas são tarefas possíveis. O rompimento com essa lógica passa pelo aprofundamento das discussões sobre raça, pelo questionamento da persistência do negro-tema nas práticas escolares, e pelo confronto do privilégio branco. Uma importante alternativa aos esforços apenas individuais nesse sentido é a atuação em rede, em forma coletiva. Assim, aos poucos, ganha-se força para a construção de novas políticas.

\section{Considerações Finais}

A pesquisa mostrou que, na relação entre professoras e alunos, a diferença racial marcada fenotipicamente reverbera não só na formação subjetiva dos estudantes, mas também afeta as docentes, pessoal e profissionalmente. Percebeu-se que todas as entrevistadas concordam que a brancura traz consigo privilégios, embora algumas se mostrem mais críticas em relação a isso que outras. A pesquisa mostrou, ainda, que o tema da identidade racial branca soou como novidade para as entrevistadas. As reações diante desse estranhamento, como também as reflexões advindas das provocações da pesquisa foram variadas. Tais fatos corroboram a visão de que a identidade branca não é una, nem estática, nem universal, daí a premente necessidade de mais investigações a respeito.

Também foi possível perceber que as entrevistadas demonstraram acreditar na escola pública como um espaço potente de transformação social. A maioria exemplificou como busca fomentar a discussão antirracista por meio de atividades didáticas e paradidáticas.

Algumas limitações da pesquisa foram o curto tempo diante do desafio do campo e a burocracia enfrentada para o acesso às escolas. Também o fato de o fenótipo da entrevistadora ser diferente do das entrevistadas é algo a ser considerado. Se a pesquisadora também fosse branca, possivelmente o pacto narcísico (in)consciente da branquitude (Bento, 2002) poderia ser um fator determinante na facilidade para expressar umas ou outras opiniões. Os presentes resultados ficam como reflexões para futuros trabalhos.

Espera-se que a discussão sobre relações raciais no campo estratégico que é a escola pública não se limite ao dia da consciência negra, à integração da história africana ao conteúdo geral ou ao reconhecimento da identidade negra. Assim como o racismo é estruturante, é importante que a discussão também penetre a estrutura escolar-curricular. Nesse exercício, o branco será também estimulado a questionar seus privilégios, a tomar consciência de seu lugar de atuação e de como contribuir com a luta antirracista. 


\section{Referências}

Almeida, S. (2018). O que é racismo estrutural?. Belo Horizonte: Letramento.

Bardin, L. (2011). Análise de conteúdo. São Paulo: Edições 70.

Bento, M. A. S. (2002). Branqueamento e Branquitude no Brasil. In I. Carone \& M. A. S. Bento (Orgs.), Psicologia social do racismo: Estudos sobre branquitude $e$ branqueamento no Brasil (pp. 25-57). Petrópolis: Vozes.

Bock, A., Gonçalves, M., \& Furtado, O. (Orgs.). (2015). Psicologia sócio-histórica: Uma perspectiva crítica em psicologia. São Paulo: Cortez.

Bock, A. M. B. (2009). Psicologia e sua ideologia: 40 anos de compromisso com as elites. In A. M. B. Bock (Org.), Psicologia e o compromisso social (2a ed., pp. 15-28). São Paulo: Cortez.

Cardoso, L. (2011). O branco-objeto: O movimento negro situando a branquitude. Instrumento - Revista de Estudo e Pesquisa em Educação, 13(1), 81-93. Recuperado de https://instrumento.ufjf.emnuvens.com.br/revistainstrumento/article/view/1176

Cardoso, L. (2017). A branquitude acrítica revisitada e as críticas. In T. Müller \& L. Cardoso (Orgs.), Branquitude: Estudos sobre a identidade branca no Brasil (pp. 33-52). Curitiba: Appris.

Carone, I., \& Bento, M. (Orgs.). (2002). Psicologia social do racismo: Estudos sobre branquitude e branqueamento no Brasil. Petrópolis: Vozes.

Conceição, V., \& Zamora, M. (2015). Desigualdade social na escola. Estudos de Psicologia (Campinas), 32(4), 705-714. doi: 10.1590/0103-166X2015000400013

Connell, R. W. (1995). Pobreza e Educação. In P. Gentili (Org.), Pedagogia da exclusão: Neoliberalismo e a crise da escola pública (pp. 11-42). Petrópolis: Vozes.

Freire, P. (1999). Educação como prática da liberdade (23a ed.). Rio de Janeiro: Paz e Terra.

Freire, P. (2005). Pedagogia do oprimido. São Paulo: Paz e Terra.

Freire, P. (2015). Pedagogia da autonomia. São Paulo: Paz e Terra.

Guzzo, R. S. L., \& Ribeiro, F. M. (2019). Psicologia na Escola: Construção de um horizonte libertador para o desenvolvimento de crianças e jovens. Estudos e Pesquisas em Psicologia, 19(1), 298-312. doi: 10.12957/epp.2019.43021

Instituto Brasileiro de Geografia e Estatística. (2017). Síntese de Indicadores Sociais: Uma análise das condições de vida da população brasileira: 2017. Rio de Janeiro: IBGE. Recuperado de https://biblioteca.ibge.gov.br/visualizacao/livros/liv101459.pdf 
Instituto de Pesquisa Econômica Aplicada (Ipea), \& Fórum Brasileiro de Segurança Pública (FBSP). (2017). Atlas da Violência 2017. Rio de Janeiro: Ipea, FBSP. Recuperado de http://www.ipea.gov.br/portal/images/170609_atlas_da_violencia_2017.pdf

Jesus, C. M. (2014). O privilégio da brancura na escola pública: Uma etnografia no colégio estadual Edvaldo Brandão Correia em Cachoeira - BA (Dissertação de Mestrado). Universidade Federal do Recôncavo da Bahia, Cachoeira, BA, Brasil. Recuperado de https://www1.ufrb.edu.br/pgcienciassociais/dissertacoes-de-mestrado/category/182014

Jesus, C. M. (2017). A persistência do privilégio da brancura: Notas sobre os desafios na construção da luta antirracista. In T. Müller \& L. Cardoso (Orgs.), Branquitude: Estudos sobre a identidade branca no Brasil (pp. 69-89). Curitiba: Appris.

Miranda, J. (2017). Branquitude invisível: pessoas brancas e a não percepção dos privilégios: verdade ou hipocrisia? In T. Müller \& L. Cardoso (Orgs.), Branquitude: Estudos sobre a identidade branca no Brasil (pp. 55-70). Curitiba: Appris.

Oliveira, L. (2007). Expressões de vivência da dimensão racial de pessoas brancas: Representações de branquitude entre indivíduos brancos (Dissertação de Mestrado). Universidade Federal da Bahia, Salvador, BA, Brasil. Recuperado de https://pospsi.ufba.br/sites/pospsi.ufba.br/files/lucio_oliveira.pdf

Penteado, T. C. Z., \& Guzzo, R. S. L. (2010). Educação e psicologia: A construção de um projeto político-pedagógico emancipador. Psicologia \& Sociedade, 22(3), 569-577. doi: 10.1590/S0102-71822010000300017

Piza, E. (2002). Porta de vidro: uma entrada para branquitude. In I. Carone, \& M. Bento (Orgs.), Psicologia Social do racismo: estudos sobre branquitude e branqueamento no Brasil (pp. 59-90). Petrópolis: Vozes.

Santos, A., Schucman, L., \& Martins, H. (2012). Breve histórico do pensamento psicológico brasileiro sobre relações étnico-raciais. Psicologia: Ciência e Profissão, 32(spe), 166175. doi: 10.1590/S1414-98932012000500012

Schucman, L. (2014). Sim, nós somos racistas: estudo psicossocial da branquitude paulistana. Psicologia \& Sociedade, 26(1), 83-94. doi: 10.1590/S0102-71822014000100010

Schucman, L., Mandelbaum, B., \& Fachim, F. (2017). Minha mãe pintou meu pai de branco: Afetos e negação da raça em famílias interraciais. Revista de Ciências Humanas, 51(2), 439-455. doi: 10.5007/2178-4582.2017v51n2p439 
Serra, L. N., \& Schucman, L. V. (2012). Branquitude e progresso: A Liga Paulista de Higiene Mental e os discursos paulistanos na contemporaneidade. Estudos e Pesquisas em Psicologia, 12(1), 288-311. doi: 10.12957/epp.2012.8321

Veiga, C. (2008). Escola pública para os negros e os pobres no Brasil: Uma invenção imperial. Revista Brasileira De Educação, 13(39), 502-516. doi: 10.1590/S141324782008000300007

Waiselfisz, J. J. (2015). Mapa da Violência 2015: Homicídios de mulheres no Brasil. Brasília: FLACSO. Recuperado de http://www.onumulheres.org.br/wpcontent/uploads/2016/04/MapaViolencia_2015_mulheres.pdf

Waiselfisz, J. J. (2016). Mapa da Violência 2016: Homicídios por arma de fogo no Brasil. Brasília: FLACSO. Recuperado de http://flacso.org.br/files/2016/08/Mapa2016_armas_web-1.pdf

\section{Endereço para correspondência}

\section{Anna Luiza Barbosa Martins}

Universidade Federal Fluminense

Coordenação de Pessoal Técnico-Administrativo, Divisão de Gestão de Lotação

Rua Miguel de Frias, 09, Reitoria, Icaraí, Niterói - RJ, Brasil. CEP 24220-900

Endereço eletrônico: annaluizabm@gmail.com

\section{Maria Helena Rodrigues Navas Zamora}

Pontifícia Universidade Católica do Rio de Janeiro

Centro de Teologia e Ciências Humanas, Departamento de Psicologia

Rua Marquês de São Vicente, 225, Edifício Cardeal Leme, Gávea, Rio de Janeiro - RJ, Brasil. CEP 22451-900

Endereço eletrônico: zamoramh@gmail.com

Recebido em: 08/10/2019

Reformulado em: 06/11/2020

Aceito em: 30/11/2020

\section{Notas}

* Mestra em Psicologia Clínica pelo Departamento de Pontifícia Universidade Católica do Rio de Janeiro.

** Doutora (1999) em Psicologia Clínica pela PUC-Rio. Docente da graduação e da pós-graduação em Psicologia da PUC-Rio.

Financiamento: os autores agradecem à Coordenação de Aperfeiçoamento de Pessoal de Nível Superior (CAPES), pela concessão de apoio financeiro à Anna Luiza Barbosa Martins, durante todo o percurso do mestrado, do qual se originou este artigo. 
Anna Luiza Barbosa Martins, Maria Helena Rodrigues Navas Zamora

Este artigo de revista Estudos e Pesquisas em Psicologia é licenciado sob uma Licença Creative Commons Atribuição-Não Comercial 3.0 Não Adaptada. 